\title{
Growth of Unicellular Forms of the Fungus Cordyceps militaris and Analysis of the Chemical Composition of their Walls
}

\author{
By DAWN B. MARKS AND BARBARA J. KELLER \\ Department of Biochemistry, Temple University School of Medicine, \\ Philadelphia, Pennsylvania, U.S.A. \\ AND A. J. GUARINO \\ Department of Biochemistry, University of Texas Medical School, \\ San Antonio, Texas, U.S.A.
}

(Accepted for publication 28 August 1971)

SUMMARY

\begin{abstract}
When Cordyceps militaris is grown in shaking culture in certain media, two large unicellular forms are produced. The walls isolated from these are similar both qualitatively and quantitatively except for their mannose content, one form containing almost twice the amount as the other $(17.5$ versus $9.6 \%$. Glucose, the predominant monosaccharide obtained by acid hydrolysis, accounts for more than half $(52$ to $60 \%)$ of the weight of the walls. The remainder is composed of galactose $(6 \%)$, hexosamine (6\%), lipid (8 to $10 \%$ ), and protein (8 to $10 \%)$.

Walls of the unicellular forms contain more glucose and protein than those of the filamentous form, but less hexosamine and lipid. Glusulase releases all of the glucose from walls of the filaments, but only half of the glucose from walls of the unicells.
\end{abstract}

\section{INTRODUCTION}

When Cordyceps militaris, which produces the antibiotic $3^{\prime}$ deoxyadenosine (Cordycepin), is grown in static culture in a medium consisting of $0.5 \%$ casein hydrolysate and $1 \%$ glucose (for review see Guarino, 1967), it forms a buoyant mycelial pad. Under other growth conditions a number of distinctly different morphological forms are produced. Since this fungus is easy to grow and the separation of its various cell types can be readily accomplished, it might serve to help elucidate mechanisms underlying cellular differentiation. We have therefore begun a series of studies comparing the morphological forms of $C$. militaris. We have previously reported on the chemical composition of the walls of hyphae (Marks, Keller \& Guarino, 1969). In the present paper we describe the growth of unicells in two types of media and compare the chemical composition of their walls with that of hyphae.

\section{METHODS}

Growth. Cultures of Cordyceps militaris (Linn.) Link, obtained from Centraalbureau voor Schimmelcultures, Baarn, Holland, were maintained on slants of oatmeal agar as previously described (Kredich \& Guarino, 1960). Conidia, removed from these slants by shaking with a sterile $0.9 \%$ saline solution, were used as the inoculum for each of the media described below. Sufficient condia were used to inoculate each flask so that their final concentration was 200 to 600 per $\mathrm{ml}$. 
All cultures were grown with reciprocal shaking at 22 to $24^{\circ}$ for four days. At this time the fungus was harvested by filtration and stored at $-20^{\circ}$.

Media. Casien hydrolysate-glucose: $0.5 \%$ casein hydrolysate (Nutritional Biochemical Corporation) and I \% glucose. Czapek-Dox: 35 g. Czapek-Dox broth (Difco) per litre. The broth contains (g./litre): sucrose, 30; $\mathrm{NaNO}_{3}, 3 ; \mathrm{K}_{2} \mathrm{HPO}_{4}, \mathrm{I} ; \mathrm{MgSO}_{4} \cdot 7 \mathrm{H}_{2} \mathrm{O}, 0.5$; $\mathrm{KCl}, 0.5$; and $\mathrm{FeSO}_{4} \cdot 7 \mathrm{H}_{2} \mathrm{O}$, 0.0I (Thom \& Raper, 1945). Moyer's sporulation broth: $50 \mathrm{~g}$. glucose; $0.56 \mathrm{~g}$. $\left(\mathrm{NH}_{4}\right)_{2} \mathrm{HPO}_{4}$; 0.I $44 \mathrm{~g}$. $\mathrm{KH}_{2} \mathrm{PO}_{4}$; 0.12 g. $\mathrm{MgSO}_{4} \cdot 7 \mathrm{H}_{2} \mathrm{O} ; 0.2$ g. Bacto-peptone (Difco); $45 \mathrm{ml}$. beer; and sufficient $\mathrm{H}_{2} \mathrm{O}$ to make one litre (Thom \& Raper, 1945).

Separation of unicells from filaments. The media were filtered through sterile glass wool which removed the filaments. The unicells were then collected by centrifugation of the filtrate.

Isolation of the wall fractions. The walls were isolated by rupturing the fungus in a Sorvall Omnimixer with glass beads for IO min. periods, centrifuging and washing with $\mathrm{H}_{2} \mathrm{O}$, and decanting the suspended walls from the sediment of glass beads (Marks et al. 1969).

Hydrolysis of the walls. The conditions for hydrolysis were essentially the same as those previously reported (Marks et al. 1969) except for a variation in the length of time the walls were heated at $100^{\circ}$. For the $\mathrm{I} \mathrm{N}-\mathrm{H}_{2} \mathrm{SO}_{4}$ hydrolysis, $\mathrm{I} 8 \mathrm{~h}$. were required for maximal release of neutral monosaccharides from the walls obtained from the fungus grown in Moyer's sporulation broth and $\mathrm{I} 2 \mathrm{~h}$. for those from Czapek-Dox broth.

Ash and $\mathrm{H}_{2} \mathrm{O}$ content. All values reported in the tables are corrected for ash and also for $\mathrm{H}_{2} \mathrm{O}$ content by procedures already described (Marks et al. 1969).

Other procedures. The procedures for thin layer chromatography, determination of neutral sugars, hexosamine, amino acids, lipid, chitin, and nucleic acids were identical to those previously described (Marks et al. 1969). Tryptophane was determined by the method of Kleinsmith \& Allfrey, 1969.

Digestion with glusulase. Walls (20 mg.) in $10 \mathrm{ml}$. sterilized buffer (0.005 M-sodium citrate, $0.036 \mathrm{M}-\mathrm{NaH}_{2} \mathrm{PO}_{4}, \mathrm{pH} 5.8$ ) were incubated with 2000 units of Glusulase (Endo Laboratories, Garden City, New York) for I $8 \mathrm{~h}$. Undigested material was removed by centrifugation and sugar determinations were performed on the supernatant solutions as described above.

\section{RESULTS}

Growth. When Cordyceps militaris was grown in static culture in casein hydrolysateglucose medium, its walls were extremely rigid and difficult to rupture. In order to obtain fungus with less rigid walls, the growth conditions were altered. The morphology of C. militaris altered as the growth conditions changed.

On changing from static to shaking culture in the casein hydrolysate-glucose medium the organism no longer grew as a buoyant pad but rather as discrete filaments. These were long, branched and septate.

In Czapek-Dox or Moyer's sporulation broth, after 2 days of shaking, unicellular forms began to appear with the filaments. By the fourth day of growth the cultures were predominantly unicellular, consisting of very short cells with no obvious septa. The unicellular forms differed from each other only slightly. In Moyer's sporulation broth the unicells were $7 \mu$ long and $2.5 \mu$ wide. The unicells grown in Czapek-Dox broth were slightly longer than these (I I $\mu$ ) but were more narrow (I.6 $\mu$ ) and less refractive (Fig. I).

We were unable to determine the origin of these unicells. Observation by phase-contrast microscopy of the cultures at different stages of growth failed to reveal any evidence of reproductive structures. Occasionally a constricted area could be observed near a hyphal 

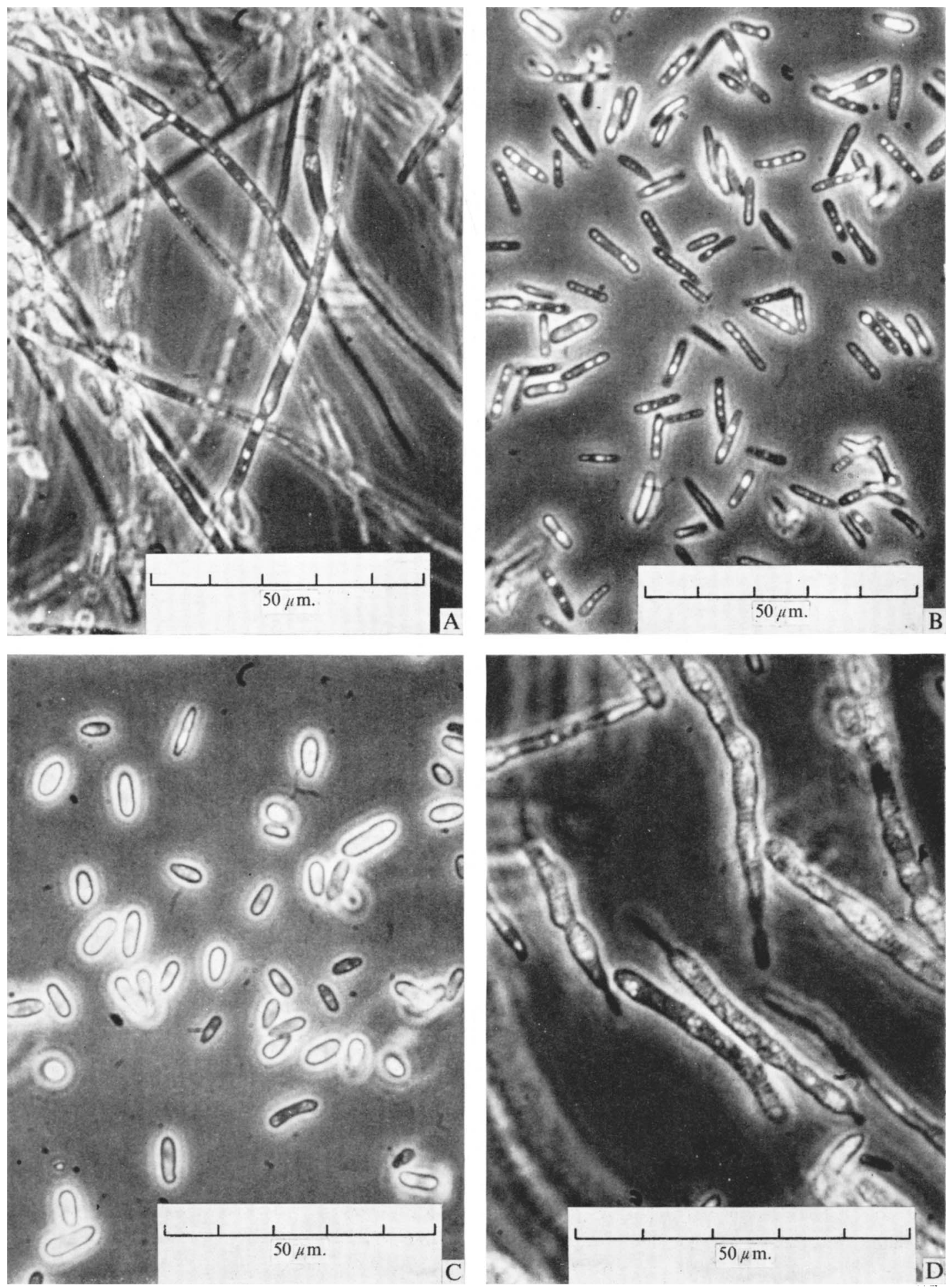

Fig. 1. Phase-contrast photomicrographs of Cordyceps militaris. (A) Fungus grown in caseinhydrolysate, glucose medium; (B) fungus grown in Czapek-Dox broth; (C) fungus grown in Moyer's sporulation broth; (D) unicells budding from hyphal tips. 
tip which led us to speculate that the unicells might be related to blastospores, originating through budding of the hyphae. The unicells themselves were not seen to bud (Fig. ID).

Since the amount of DNA, RNA and protein per ml. in each culture, as well as the dry weight of fungus, continued to increase during the first week of growth in each of the three media, the unicells were actively growing.

At the time of inoculation the $\mathrm{pH}$ of the Czapek-Dox broth was 7.2. By the time unicells were observed in the culture two days later, the $\mathrm{pH}$ had decreased slightly to $6 \cdot 8$. In casein hydrolysate, glucose, the $\mathrm{pH}$ decreased from 6.4 to 4.7 during the first two days of growth and in Moyer's sporulation broth the decrease was even greater (from 6.5 to $2 \cdot 8$ ). In each of the media the $\mathrm{pH}$ remained constant for at least one week after the initial decrease.

Filtration through sterile glass wool of four day cultures grown in Czapek-Dox or Moyer's sporulation broth freed the media of filaments. When the filtrate (depleted media containing the unicells) was returned to the shaker, no obvious change in shape or size of the cells occurred over a period of 7 days. However, if the unicells from four-day cultures were collected by filtration and centrifugation, washed with water and returned to fresh media, they all elongated at a rapid rate. Within one day each of the unicells had developed into a long filament. After two days in Czapek-Dox or Moyer's sporulation broth new unicells began to appear.

Analysis of walls. Wall fractions from unicells obtained from Czapek-Dox and Moyer's sporulation broths were isolated and hydrolysed in $\mathrm{I} \mathrm{N}-\mathrm{H}_{2} \mathrm{SO}_{4}$ or in $6 \mathrm{~N}-\mathrm{HCl}$. The results of analyses of these walls and their hydrolysates are listed in Table $\mathrm{I}$ and 2.

\section{Table I. Chemical analyses of Cordyceps wall fractions}

All values as percent of the dry wall weight corrected for the ash content. The carbohydrate values are those for the anhydro-sugars.

\begin{tabular}{|c|c|c|c|}
\hline & \multicolumn{3}{|c|}{ Growth medium } \\
\hline & \multirow{2}{*}{$\begin{array}{c}\text { (Filaments) } \\
\text { Casein- } \\
\text { hydrolysate, } \\
\text { glucose* }\end{array}$} & \multicolumn{2}{|c|}{ (Unicells) } \\
\hline & & Czapek-Dox & $\begin{array}{l}\text { Moyer's sporu } \\
\text { lation broth }\end{array}$ \\
\hline Glucose & $46 \cdot 0$ & $52 \cdot 0$ & $60 \cdot 0$ \\
\hline Galactose & $7 \cdot 0$ & $5 \cdot 7$ & $6 \cdot I$ \\
\hline Mannose & $9 \cdot 0$ & $17 \cdot 5$ & $9 \cdot 6$ \\
\hline Hexosamine & II $\cdot 0$ & $5 \cdot 5$ & $6 \cdot 8$ \\
\hline Protein $†$ & $6 \cdot 0$ & $8 \cdot 2$ & $9 \cdot 7$ \\
\hline \multicolumn{4}{|l|}{ Lipid } \\
\hline Total & I4. I & $8 \cdot 0$ & $10 \cdot 4$ \\
\hline Readily extracted & $10 \cdot 7$ & $4^{\circ} 0$ & 6.6 \\
\hline Bound & $3 \cdot 4$ & $4 \cdot 0$ & $3 \cdot 8$ \\
\hline Sum & $93 \cdot 8$ & $96 \cdot 9$ & $102 \cdot 6$ \\
\hline
\end{tabular}

The walls of the unicellular forms were composed mainly of carbohydrates (8I to $83 \%$ ). When the polymers were hydrolysed by acid, glucose was found to be the predominant monosaccharide ( 52 to $60 \%$ ), while galactose, mannose, and hexosamine made up the remainder of the carbohydrate component. Thin-layer chromatograms indicated that there were no more than minute traces of other sugars in the hydrolysates. A positive van Wisselingh test indicated that at least some of the hexosamine was present as chitin. 
The protein component of the walls contained 15 amino acids in substantial quantities and small amounts of tryptophane, cysteine and methionine. The total protein content of the walls as determined by summation of the values for the individual amino acids was 8 to $10 \%$.

An additional 8 to $10 \%$ of the walls was composed of lipid some of which was readily extracted by lipid solvents, the remainder requiring pretreatment with acid (indicated in Table I as 'bound' lipid).

The nucleic acid content was very low, indicating little cytoplasmic contamination.

Glusulase treatment. Glusulase, an enzyme mixture from the snail gastrointestinal tract, released half of the glucose from the wall polymers of the unicells (Table 3). By contrast, all of the glucose was released from walls of filaments grown in casein hydrolysate, glucose medium.

\section{Table 2. Amino-acid analyses of protein components of Cordyceps wall fractions}

All values as percentage of the dry wall weight corrected for the ash content.

\begin{tabular}{lccc} 
& \multicolumn{3}{c}{ Growth medium } \\
$\begin{array}{c}\text { Amino } \\
\text { acid }\end{array}$ & $\begin{array}{c}\text { (Filaments) } \\
\text { Casein- } \\
\text { hydrolysate, } \\
\text { glucose* }\end{array}$ & Czapek-Dox & $\begin{array}{c}\text { Moyer's sporu- } \\
\text { lation broth }\end{array}$ \\
Asp & 0.657 & 0.934 & I.I I 5 \\
Thr & 0.665 & 0.926 & 0.983 \\
Ser & 0.534 & 0.689 & 0.846 \\
Pro & 0.477 & 0.728 & 0.855 \\
Glu & 0.672 & 0.766 & 1.058 \\
Gly & 0.310 & 0.390 & 0.469 \\
Ala & 0.448 & 0.592 & 0.721 \\
Val & 0.343 & 0.425 & 0.454 \\
Half Cys & 0.000 & 0.102 & 0.079 \\
Met & 0.107 & 0.104 & 0.132 \\
Ile & 0.247 & 0.200 & 0.271 \\
Leu & 0.429 & 0.437 & 0.534 \\
Tyr & 0.219 & 0.229 & 0.297 \\
Phe & 0.262 & 0.268 & 0.233 \\
Lys & 0.398 & 0.762 & 0.766 \\
His & 0.143 & 0.177 & 0.205 \\
Arg & 0.377 & 0.430 & 0.675 \\
Trp & 0.042 & 0.023 & 0.000 \\
Sum & 6.33 & 8.18 & 9.69
\end{tabular}

* Included for comparison. Average of values previously reported (Marks et al. 1969).

$\dagger$ Determined by the method of Kleinsmith \& Allfrey, 1969. All other values were determined on acid hydrolysates with an automatic amino-acid analyzer.

Table 3. Release of glucose from walls by glusulase

$\begin{array}{lcc} & \begin{array}{c}\text { Free glucose } \\ \text { (released by } \\ \text { Glusulase) } \\ \text { (mg./I00 mg. }\end{array} & \begin{array}{c}\text { Total } \\ \text { glucose } \\ \text { wrowth } \\ \text { medium }\end{array} \\ \text { in wall }(\%) & \\ \text {-hydrolysate, glucose } & 47 \cdot 3 & 100 \\ \text {-Dox } & 28 \cdot 6 & 55 \\ \text { 's sporulation broth } & 31 \cdot 9 & 53\end{array}$




\section{DISCUSSION}

The production of unicells by Cordyceps militaris appeared to be related to the chemical composition of the medium. Since the temperature and shaking rate were constant for all media, these factors could not have influenced the morphology. The $\mathrm{pH}$ also did not appear to initiate unicell production, since unicells were produced at $\mathrm{pH} 6.8$ in Czapek-Dox broth and at $\mathrm{pH} 2.8$ in Moyer's sporulation broth while filaments resulted at an intermediate value $(4 \cdot 7)$.

The sugar concentration might have caused the form of the organism to change. The media-yielding filaments contained $\mathrm{I} \%$ glucose while unicells were produced in media with higher sugar concentrations ( $3 \%$ sucrose and $5 \%$ glucose). The nitrogen source might also have been a deciding factor since unicells were produced on inorganic sources $\left(\mathrm{NaNO}_{3}\right.$ or $\left(\mathrm{NH}_{4}\right)_{2} \mathrm{HPO}_{4}$ ) while filaments occurred on an organic nitrogen source (casein hydrolysate).

We performed some preliminary experiments to determine which component of the medium was responsible for unicell production and found that, in media containing only $0.5 \%$ casein hydrolysate and glucose, the organism shifted from a predominantly filamentous to a predominantly unicellular form when the amount of glucose was increased from I to $10 \%$. In this case, as in the other unicell-producing media, the organism grew as filaments for two days before the buds which produced unicells began to appear at the hyphal tips. By the fourth day the culture was composed mainly of unicells. Therefore, although a high initial sugar concentration resulted in unicell production, the age of the culture also played a part.

Unicells produced in Moyer's sporulation broth or Czapek-Dox broth and filaments grown in casein hydrolysate-glucose, had walls which were quite similar qualitatively. However, quantitative differences did occur, not only between the unicells and the filaments, but also between the two different types of unicells.

The unicell walls contained more glucose and protein than did those of the filaments. However, the amount of hexosamine in the filamentous walls was almost double that in the unicell walls, and the lipid content of the filaments was also higher.

The most striking variation was in the mannose values which differed between the two types of unicells, the walls from those grown in Czapek-Dox broth containing almost double the amount of mannose found in walls from unicells grown in Moyer's sporulation broth.

The protein found in the wall preparations of the filaments and of the two types of unicells appeared to be similar. The amino acid analyses indicated that the protein was acidic, acidic and hydroxy amino acids together accounting for 39 to $4 \mathrm{I} \%$ of the total protein.

Glucose polymers made up the major portion of the walls. The experiments with Glusulase suggested that the glucose polymers of the filaments were constructed in a different manner from those in the unicells. Glusulase completely degraded the glucose polymers of the filaments releasing free glucose. However, only half of the glucose in the unicell walls was degraded to free glucose by this enzyme mixture. These observations indicated that the type of linkage between the glucose monomers differed in the two types of cells. Possibly different types of branching occur.

Our studies on Cordyceps militaris support the conclusions of Bartnicki-Garcia (1968) who has recently reviewed the information available on fungal wall structure and has observed that morphogenesis is accompanied by changes in wall content that are mainly quantitative. Changes in the amount of wall mannan have been found following the yeast 
to mould transition in dimorphic fungi, but the direction of the changes is often conflicting. Quantitative changes in wall composition have also been found in the transition from spore to hypha. In the organisms studied so far, except for Mucor rouxii, sporogenesis and spore germination occur with retention of the basic chitin-glucan structure of the wall. In C. militaris we have found that only quantitative changes in wall composition occur athough the morphology of the organism has undergone a remarkable alteration.

This work was supported in part by grants from the National Science Foundation (NSF GB 7967). We thank Dr Prince Brigham of Temple University School of Medicine for the use of his amino-acid analyser.

\section{REFERENCES}

BARTNICKI-GARCIA, S. (1968). Cell wall chemistry, morphogenesis, and taxonomy of fungi. Annual Review of Microbiology 22, 87-108.

Guarino, A. (1967). Cordycepin. In Antibiotics, vol. I, pp. 468-480. Edited by D. Gottlieb and P. Shaw. New York: Springer-Verlag.

Kleinsmith, K. \& Allfrey, V. (1969). Nuclear phosphoproteins. I. Isolation and characterization of a phosphoprotein fraction from calf thymus nuclei. Biochimica et biophysica acta 175, $123-135$.

Kredich, N. \& GUarino, A. (1960). An improved method of isolation and identification of cordycepin. Biochimica et biophysica acta 4I, 363-365.

Marks, D., Keller, B. \& Guarino, A. (1969). The composition of the cell wall fraction of the fungus, Cordyceps militaris. Biochimica et biophysica acta 183, 58-64.

THом, C. \& RAPER, K. (1945). In A Manual of the Aspergilli, p. 32. Baltimore: Williams and Wilkins. 